\title{
Optimal Dispatch of a Multiple Energy Carrier System Equipped With a CCHP
}

\author{
A.Sheikhi, A.M.Ranjbar, F.Safe \\ Department of Electrical Engineering \\ Sharif University of Technology \\ Tehran, Iran
}

Phone/Fax number: 0098912 6613840,e-mail: sheikhi@ee.sharif.edu,ranjbar@sharif.edu, Safe@ee.sharif.edu

\begin{abstract}
With the development of distributed generation (DG) technologies and the implementation of policies to encourage their applications, The Combined Cooling, Heating, and Power (CCHP) systems is expected to play a greater role in the commercial buildings in the future. CCHP is a promising efficiency improvement and carbon mitigation strategy, but careful operation mode is required to achieve a reasonable system performance according to energy consumption characteristics of buildings and technical features of equipments [1].

This paper presents an energy dispatch method which minimizes the cost of energy (e.g., cost of electricity from the grid and cost of natural gas into the gas turbine and boiler) base on the energy hub concept and by regarding carbon market rules. The system includes combined heating power (CHP) module, auxiliary boiler, absorption chiller, utility grid and electrical, thermal, and cooling loads. In fact, by solving this model, optimal energy flow will be determined regarding both the amounts of electric, thermal, and cooling loads in each time interval and prices of electricity and natural gas at the same time, by considering environmental constrains. In the cost function of this model, the total economic benefit of this system is maximized during total daily operation time.

The results of an optimal operation model have been discussed economically and a case study has been investigated.
\end{abstract}

\section{Key Words}

combined cooling heating and power (CCHP), energy hub, optimal operation, $\mathrm{CO}_{2}$ emission

\section{Introduction}

Traditional power plants convert about $30 \%$ of the fuel's available energy into electric power[2]. The majority of the energy content of the fuel is lost at the power plant through the discharge of waste heat. Further energy losses occur in the transmission and distribution of electric power to the individual user. Inefficiencies and pollution issues associated with conventional power plants provide the motivation for developments in "onsite and near-site" power generation.

To overcome mentioned defects today as a supplement for conventional large-scale power generation system, distributed generation (DG) technologies have got more comprehensive attention. Distributed generation (DG) represents an alternative for generating electricity (and heat) close to the point of demand. One of the keys to the prosperity of fossil-fuelled DG is the ability to use the waste heat from electricity generation, raising total system efficiencies up to $90 \%$ (higher heating value) in the best applications. The high efficiencies of such applications, commonly called combined heat and power
(CHP), offer both reduced costs and significant reductions of $\mathrm{CO}_{2}$ emissions. Other factors may also drive increased deployment of DG in the future, including enhanced reliability and security, reduced need for transmission and distribution upgrades, and simpler plant sitting [5-7]. DG also gives prominence to the government's Kyoto Protocol Target Achievement Plan [1].

In addition to recover the waste heat for heating purpose it is also possible to transform the waste heat by-product in a CHP system, such as hot water or steam, into useful cooling by using an absorption chiller. Unlike a conventional electrical chiller that uses mechanical energy, the absorption chiller uses heat in a refrigeration cycle to provide cooling. Combined cooling, heating, and power (CCHP) systems use reciprocating internal combustion engines, turbine engines, and even fuel cells to generate electrical power while recovering waste heat for heating or cooling (through absorption chillers) purposes. CCHP systems produce both electric and useable thermal energy onsite or near site, converting as much as $80 \%$ of the fuel into useable energy [8].

Like a traditional power grid that the objective of economic dispatches (ED) is to determine the allocation of electric power for different generating units in order to minimize the total generation cost subject to both technological and physical constraints, ED in CHP or CCHP is assuming an increasingly important role since it provides an economic solution to fulfilling the demands on electric power, district heat and cooling and It is deemed as an effective way of increasing overall energy efficiency[9].

CCHP plants face fluctuating demands for heating cooling and power. Thus, there are more uncertain factors in CCHP than in pure power dispatch [1-2]. Inevitably, more design objectives coupled with tighter constraints need to be incorporated. As a subset of unit commitment, power dispatch is a major function in energy management systems (EMS).

In this paper an optimal dispatch of energy hub [3] equipped with CCHP is considered and the optimum operation of CCHP systems for different climate conditions is exemplified based on energy cost and operational system emissions.

The contents of this paper are organized into six sections. Following this introduction, the energy hub concept and a brief overview of the Energy hub modeling is presented in Section II. To find the optimum operational point, Section III provides detailed formulations on the problem. In section IV, the presented approach is demonstrated in examples. Finally, section $\mathrm{V}$ concludes and summarizes this paper. 


\section{Energy Hub Concept and Modelling}

Some conceptual approaches for an integrated view of transmission and distribution systems with distributed generation have been published. Besides "energy-services supply systems"[10], "basic units"[11], and "micro grids"[12], so-called "hybrid energy hubs", are suggested, where the term "hybrid" represent the use of multiple energy carriers[13-14]. An energy hub is considered a unit where different energy carriers can be converted, conditioned, and maybe stored. It represents an interface between different energy infrastructures and/or loads. Energy hubs consume power at their input ports which is connected to, e.g. electricity and natural gas infrastructures, and prepare certain required energy services such as electricity, heating, cooling, and compressed air at their output ports [3]. Energy hubs include two basic elements: direct connections and converters. Direct connections are used to deliver an input power to the output without converting. Converter elements are used to change carriers into other forms or qualities. Some of these convertors to mention are gas turbines, combustion engines and fuel cells. Figure 1 demonstrates an example of an energy hub.

The components within the hub may create extra connections between inputs and outputs. For instance, the electricity load connected to the hub in Figure 1 can be met by consuming all power directly from the electricity grid or generating part or all of the required electricity from natural gas. This redundancy in supply results in a significant benefit, which can be achieved using energy hubs: Reliability of supply can be enhanced from the load's perspective because it is not completely dependent on a single supply.

From a system point of view, combining and coupling different energy carriers show a number of potential benefits over conventional, decoupled energy supply.

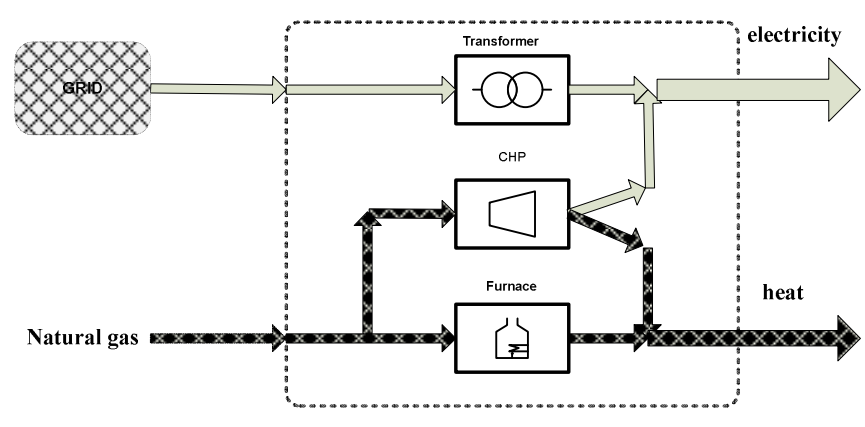

Fig. 1. Example of an energy hub that contains an electric transformer, a CHP and a gas furnace

The energy hub is an archetype with no limitations to the size of the modeled system. Single power plants or industrial buildings as well as bounded geographical areas such as entire towns can be modeled as energy hubs. The model of the system is formulated below.

In the system under study, the energy hub represents a general consumer as a household which uses both electricity and gas. The hub is connected to a large gas network and the electricity network.
The hub consumes electric power $P_{e}$ and gas $P_{\mathrm{g}}$ and provides energy to its electric load $L_{\mathrm{e}}$ and its heat load $L_{\mathrm{h}}$. The hub contains converter devices in order to fulfill their energy load requirements. For energy conversion, the hub contains a CHP device and a furnace. The CHP device couples the two energy systems at the same time that produces electricity and heat from natural gas. Depending on the prices of energy and load profiles, the CHP device is utilized differently. At high electricity prices, the electric load is supplied by CHP more than normal times. The thereby produced heat is then used to supply the thermal load. At low electricity prices, the electric load is rather supplied directly by the electricity network and the gas is used for supplying the thermal load via the furnace. Hence, there are several ways in which electric and thermal load demands can be fulfilled. This redundancy increases the reliability of supply and simultaneously provides the possibility for optimizing the input energies, e.g. using criteria such as cost, availability, emissions, etc.

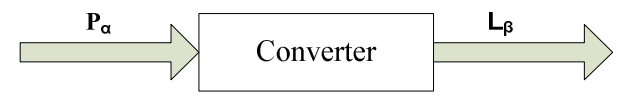

Fig. 2. Model of power converter

Consider a converter device as indicated in Fig (2) that converts an input energy carrier $\alpha$ into $\beta$. Input and output power flows are not independent; we consider them to be coupled

$$
\mathrm{L}_{\beta}=\mathrm{c}_{\alpha \beta} \times \mathrm{P}_{\alpha}
$$

Where $\mathrm{P}_{\alpha}$ and $\mathrm{L}_{\beta}$ are the steady state input and output powers, respectively $\mathrm{c}_{\alpha \beta}$ is the coupling factor; it defines the coupling between input and output power flow. For a simple converter device with one input and one output, the coupling factor corresponds to the converter's steady state energy efficiency. $\operatorname{Fig}(2)$.

A general model covering all types of couplings can be stated that all power inputs $\mathrm{P}_{\alpha}, \mathrm{P}_{\beta}, \ldots, \mathrm{P}_{\omega}$ and outputs $\mathrm{L}_{\alpha}, \mathrm{L}_{\beta}, \ldots, \mathrm{L}_{\omega}$ in vectors and, respectively, enables the formulation of multiinput multi-output power conversion analog to (2)

$$
\left[\begin{array}{l}
\mathrm{L}_{\alpha} \\
\mathrm{L}_{\beta} \\
\cdot \\
\cdot \\
\cdot \\
\mathrm{L}_{\omega}
\end{array}\right]=\left[\begin{array}{cccccc}
C_{\alpha \alpha} & C_{\beta \alpha} & \cdot & \cdot & \cdot & C_{\omega \alpha} \\
C_{\alpha \beta} & C_{\beta \beta} & \cdot & \cdot & \cdot & C_{\omega \beta} \\
\cdot & \cdot & \cdot & & \cdot \\
\cdot & \cdot & \cdot & \cdot \\
\cdot & \cdot & & \cdot & \cdot \\
C_{\alpha \omega} & \cdot & & & & C_{\omega \omega}
\end{array}\right]\left[\begin{array}{l}
\mathrm{P}_{\alpha} \\
\mathrm{P}_{\beta} \\
\cdot \\
\cdot \\
\mathrm{P}_{\omega}
\end{array}\right]
$$

\section{Proposed Optimization Methodology}

Optimal operation of a CCHP system is not easy to achieve, especially when it has been considered as an element of a single energy hub. This difficulty arises from this fact that operational conditions such as the costs of fuel and electricity for the energy generation systems and also electric, cooling, and heating load demand from a building vary in the time [4]. The price of electricity changes by the time of day. Suitable opti- 
mization method can increase efficiency of CCHP and energy hub and also decrease operational cost in both cases.

This paper implements a program that identifies the amount of cooling, heating, and electric energy to be produced in an energy hub with CCHP system in a time period for a given load.

In contrast to converters with one input and one output, the coupling factors are in general no longer equal to converter efficiencies when considering multiple inputs and outputs. Since the total input of one energy carrier may split up to several converters (at input junctions), so-called dispatch factors have to be introduced that define the dispatch of the total input to the devices converting this carrier. Consider for instance the natural gas input of the hub shown in Fig. 1 that splits up to the gas turbine and the boiler. A factor can be introduced, where $\gamma$ times the total input power flows into the gas turbine and $(1-\gamma)$ times the input is converted by the boiler, with $0<\gamma$ $<1$. In general, each coupling factor contains products of dispatch factors and converter efficiencies. In the energy hub equipped with CCHP, besides $\gamma$, there are two other important factors, $\alpha$ and $\beta$, that determine how much of generated heat from gas turbine and boiler streams to the absorption chiller. Fig. 3 clearly demonstrates factors $\gamma, 1-\alpha$ and $1-\beta$ in a single energy hub system with CCHP and boiler.

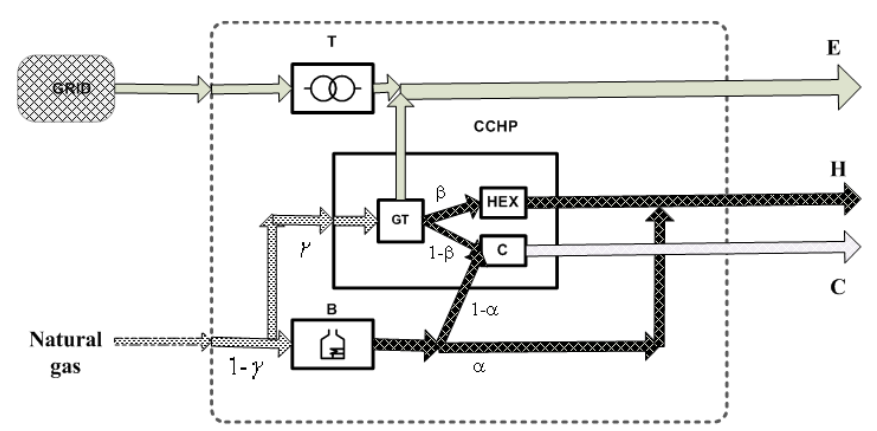

Fig. 3. An energy hub that contains an electric transformer(T), a CCHP(gas turbine (GT), chiller(C), heat exchanger(HEX)) and a boiler(B) E: electrical load, C: cooling load, H: heating load

Optimization of above parameters has a significant effect on overall efficiency of energy hub and decrease the operational cost apparently.

To investigate optimized value of these parameters, the following objective function has to be minimized which is considered the total energy cost for the energy hub system:

$$
\begin{aligned}
& L_{e}=\eta_{e e} P_{e}+\gamma \eta_{g e}^{C H P} P_{g} \\
& L_{h} \leq\left((1-\gamma) \alpha \eta_{g h}^{B}+\gamma \eta_{g h}^{C H P} \beta\right) P_{g} \\
& L_{c}=\left((1-\gamma)(1-\alpha) \eta_{g h}^{B}+\gamma \eta_{g h}^{C H P}(1-\beta)\right) \\
& \times \eta^{\text {chiller }} P_{g} \\
& P_{g}^{\min } \leq P_{g} \leq P_{g}^{\text {Max }} \\
& P_{e}^{\text {min }} \leq P_{e} \leq P_{e}^{\text {Max }}
\end{aligned}
$$

$0 \leq \gamma \leq 1$

$0 \leq \beta \leq 1$

$0 \leq \alpha \leq 1$

$\operatorname{Min}\left\{\sum_{n=1}^{24} P_{e}(n) e(n)+P_{g}(n) g(n)+P_{e}(n) \chi_{e}+P_{g}(n) \chi_{g}\right\}$

Where:

$\mathrm{L}_{\mathrm{e}}$ is electrical load

$\mathrm{L}_{\mathrm{h}}$ is heating load

$\mathrm{L}_{\mathrm{c}}$ is cooling lood

$\gamma, \alpha, \beta$ are dispatch factors

$\eta_{e e}$ is the transformer efficiency

$\eta_{g h}^{B} \quad$ is the boiler efficiency

$\eta_{g e}^{C H P}$ is the electrical efficiency of CHP

$\eta_{g h}^{C H P}$ is the heating efficiency of CHP

$\eta^{\text {chiller }}$ is the efficiency of the absorption chiller

Today the threat of global warming and climate change has created worldwide concerns. As a result many countries reached and signed agreements such as Kyoto in order to reduce greenhouse gas emissions. Hence, $\mathrm{CO}_{2}$ emission consideration is highlighted as one of the effective factors on power generation. Based on the social costs of carbon emissions, assuming that the price of carbon is around $\$ 30$ (US) per ton $(0.03 \$$ per $\mathrm{Kg})$ which needs to increase with inflation rates [15]. $\chi_{e}$ and $\chi_{g}$ are price of carbon in $\$$ per KWh for using electricity and natural gas as energy hub input respectively and this factors different from site to site.

$\mathrm{g}(\mathrm{n})$ and $\mathrm{e}(\mathrm{n})$ are prices of natural gas and electricity for consumers in \$ per KWh that varies among different regions.

Note that the feasible region of the optimization problem is defined by different constraints. An equality constraint is given by the equation that describes the power flow through the hub. Inequalities arise from limitations of the hub's input power vector and the power inputs to the individual converters. The relation between the hub input vector and the converter input vector is given (3), (4) and (5). Lower and upper limits of CCHP and transformer rates are defined as (6) and (7) respectively. Limitation of the dispatch factors, (8), by zero and one has to be regarded as well.

\section{Case Study}

The energy load profiles of a building depend on the climate conditions. Cities with different climate conditions were selected to obtain different building electric, cooling, and heating load profiles.

These cities are: Minneapolis, San Francisco, and Miami. The model presented in this paper has been applied to a Hotel building as an energy hub [16].

Hotels usually operate 7,800 to 8,760 hours year. Most hotels, particularly larger hotels, have large annual electricity consumptions. They also have high thermal needs [8]. This translates into a high thermal to electrical ratio of about 1.2 for the average hotel [1-8], indicating hotels can beneficially recapture waste heat generated by a CCHP system. The high number of operating hours and the rather constant electrical and 
thermal loads, therefore, make hotels great candidates for CCHP system.

In this case study, operational costs of three 100,000 squarefeet hotels as an energy hub are calculated in three different scenarios:

\section{1. energy hub equipped with CCHP \\ 2. energy hub equipped with CHP \\ 3. energy hub without CHP}

To acquire the electric, cooling, and heating hourly loads for hotels in selected cities general information [16] of these buildings is presented in Figure 4, 5 and 6.

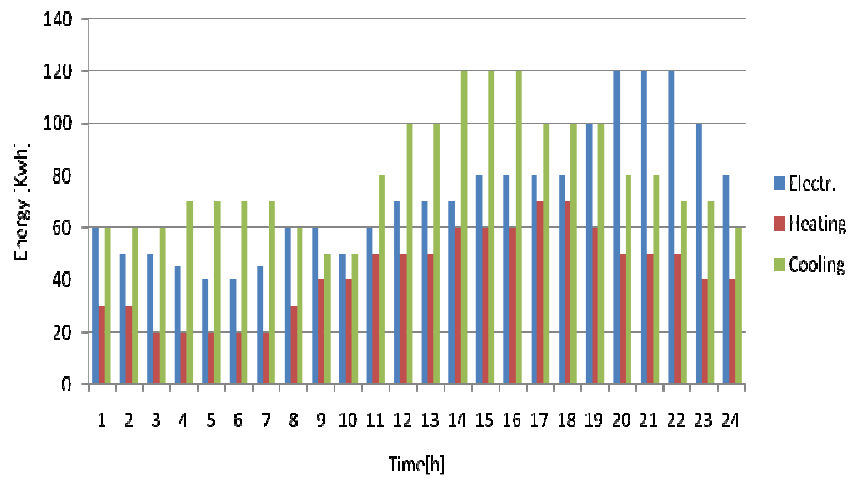

Fig 4. Energy consuption for a hotel in Miami

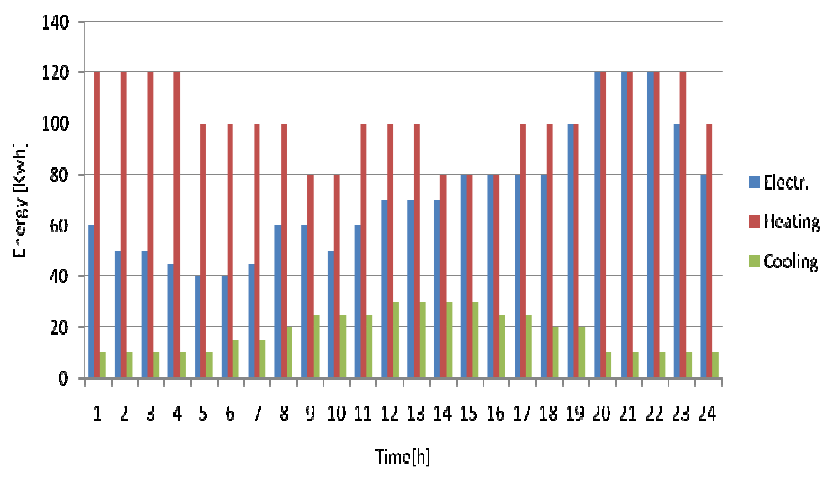

Fig 5. Energy consuption for a hotel in Minneapolis

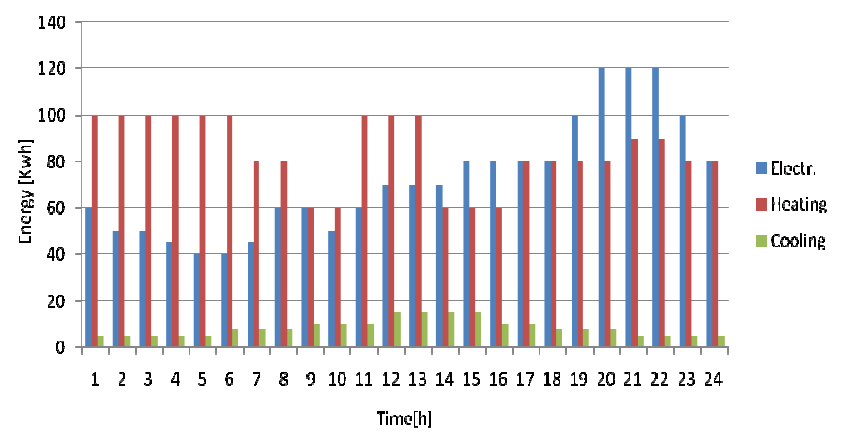

Fig 6. Energy consuption for a hotel in San Francisco

The reference building uses electricity from the grid to satisfy the electric demand and natural gas to satisfy the heating demand.
If hotel as an energy hub equipped with CCHP (state 1) then the electricity demand includes the electricity needed for lights some equipments and natural gas was used as fuel for both $\mathrm{CCHP}$ and boiler to satisfy the cooling and heating demands. In State 2, the electricity demand includes the electricity needed for lights, some equipment and to power the vapor compression system to satisfy the cooling demand. Natural gas was used as fuel for both CHP and boiler to satisfy the heating demand.

In state 3 (reference case), the electricity demand includes the electricity needed for lights, some equipment and to power the vapor compression system to satisfy the cooling demand. Natural gas was used as fuel for boiler to satisfy the heating demand. In states 2 and 3 the vapor compression system of the reference case was assumed to have a coefficient of performance (COP) of 4.

The costs for electricity and natural gas for the cities described above are shown in figures 7, 8 and 9.[17-18]

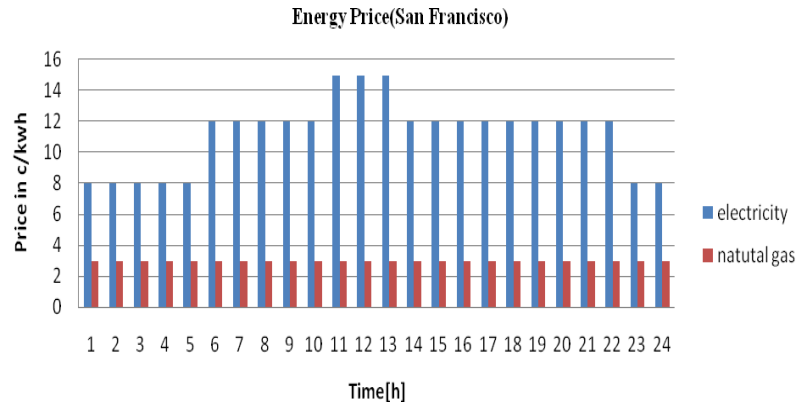

Fig 7. Energy price in San Francisco Energy Price(Miami)

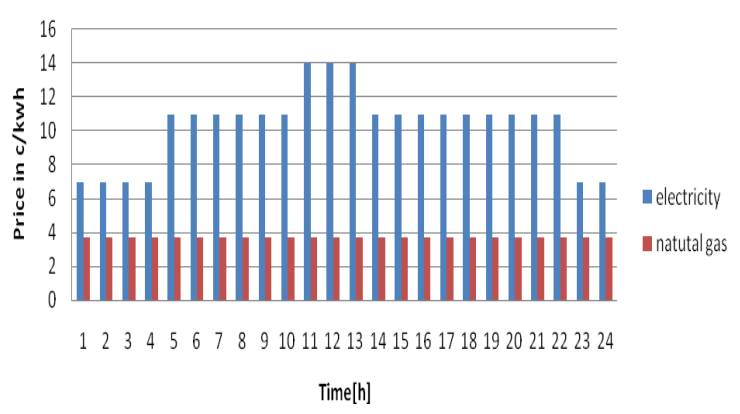

Fig 8. Energy price in Miami

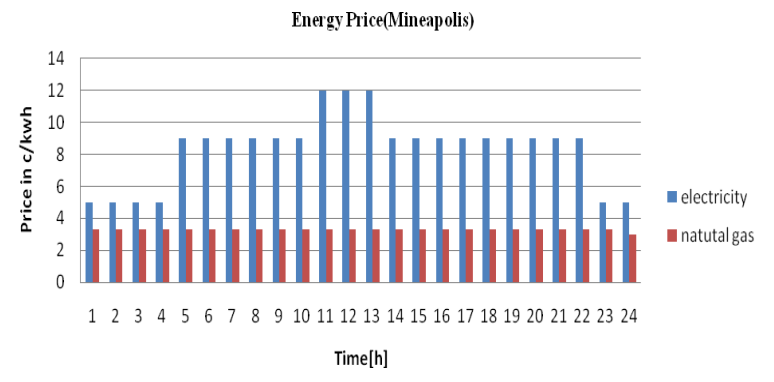

Fig 9. Energy price in Minneapolis

The $\mathrm{CO} 2$ emission factors for electricity and natural gas for the cities presented above are listed in Table 1[19]. 
Table 1: Carbon dioxide emissions conversion factors for electricity and natural gas $[\mathrm{kg} / \mathrm{kwh}]$

\begin{tabular}{l|ll}
\hline \multicolumn{1}{c}{ City } & Electricity[kg/kWh] & $\begin{array}{l}\text { Natural } \\
\text { Gas }[\mathrm{kg} / \mathrm{kWh}]\end{array}$ \\
\hline Minneapolis & 0.826 & 0.2 \\
San Francisco & 0.440 & 0.2 \\
Miami & 0.662 & 0.2 \\
\hline
\end{tabular}

Taking in to account that the price of carbon is around $\$ 30$ (US) per ton (0.03\$ per $\mathrm{Kg})$ [15-19] hence as Table 2 :

Table 2: Carbon dioxide emissions conversion factors for electricity

\begin{tabular}{l|ll}
\multicolumn{3}{c}{ and natural gas [cent/kwh] } \\
\hline City & $\chi_{e}[$ cent/kWh] & $\chi_{g}$ [cent $\left./ \mathrm{kWh}\right]$ \\
\hline Minneapolis & 2.47 & 0.6 \\
San Francisco & 1.32 & 0.6 \\
Miami & 2 & 0.6 \\
\hline
\end{tabular}

A $100 \mathrm{KWe}$ generator set was used in the simulation.

The typical energy distribution for internal combustion engines is provided [20]. It shows that $30 \%$ of the fuel energy is converted to heat energy rejected through the coolant and another $30 \%$ of the fuel energy is rejected as heat through the exhaust gas. The total efficiency of heat exchangers for the coolant and exhaust gas is estimated to be 0.85 , and the total fuel-to-thermal-energy conversion efficiency (i.e., total heat recovered from the engine) is then calculated to be $(30 \%+30 \%)(0.85)=51 \%$.

The boiler thermal efficiency $\left(\eta_{g h}^{B}\right)$ was assumed to be $90 \%$. The total efficiency of the cooling components (chiller efficiency) was estimated by considering the Coefficient of Performance (COP), amount of heat moved per unit of input work required, of an absorption chiller and the efficiency of an air handling unit.

A COP of 0.7 is used for the absorption chiller and an efficiency of 0.85 is used for the air handling unit. The total efficiency of cooling components is then calculated to be $(0.7)$ $(0.85) * 100=60 \%$. The total efficiency of the heating components is estimated $85 \%$ which is an efficiency of the air handling unit.

The thermal energy losses due to energy transport/transmission in the network are neglected in this simulation because the pipes are well insulated in the facility.

A summary of energy hub elements' efficiency information for the algorithm used in the simulation is listed in Table 3.

Table 3: efficiency of hub elements

\begin{tabular}{ll|l}
\hline Efficiency constraint & & \\
\hline transformer efficiency & $\eta_{e e}$ & 0.96 \\
boiler efficiency & $\eta_{g h}^{B}$ & 0.90 \\
electrical efficiency of CHP & $\eta_{g e}^{C H P}$ & 0.30 \\
heating efficiency of CHP & $\eta_{g h}^{C H P}$ & 0.51 \\
efficiency of the chiller & $\eta^{\text {chiller }}$ & 0.60 \\
\hline
\end{tabular}

The results obtained from the energy hub model described in Section 3 are presented. Simulations with a time step of $1 \mathrm{~h}$ were performed to optimize CCHP operation with respect to the cost for the selected cities. The results were obtained using three different objective functions with respect to the three mentioned scenarios in each simulation for each city.

Figures 10,11 and 12 depict dispatch factors in scenario 1 for each city.

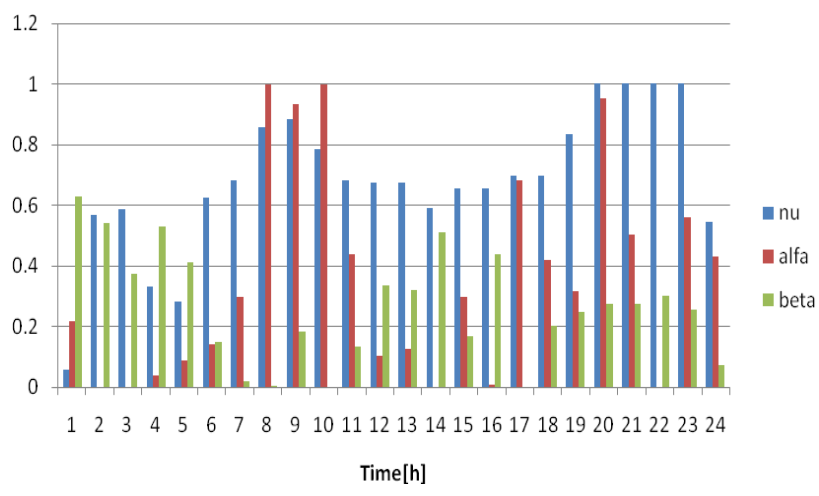

Fig 10. Dispatch factors for a hotel in Miami in scenario 1

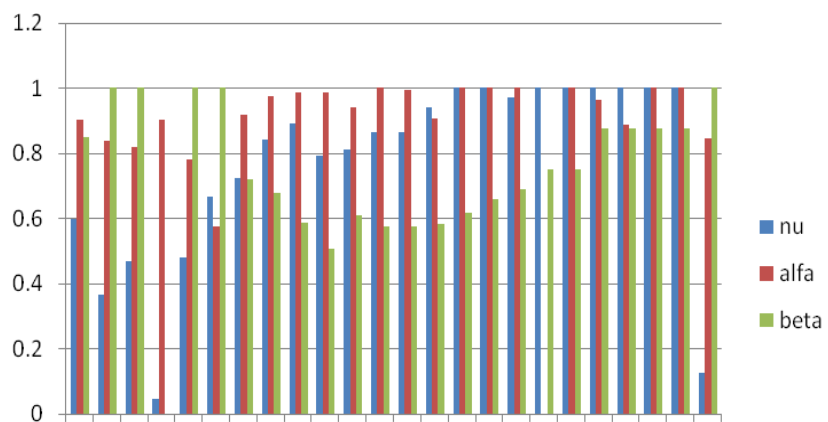

12334567899101112131415161718192021222324 Time[h]

Fig 11. Dispatch factors for a hotel in Minneapolis in scenario 1

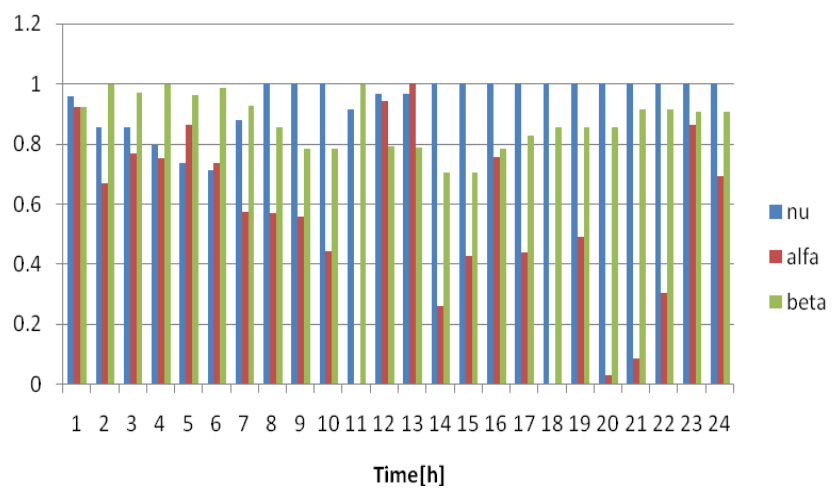

Fig 12. Dispatch factors for a hotel in San Francisco in scenario 1

Table 4 lists the energy price in each hotel in a day. 
Table 4: Energy price in a day $(\mathrm{Ee}+\mathrm{Eg})[\$ /$ day $]$

\begin{tabular}{lllll}
\hline & Scenario & $\mathbf{1}$ & $\mathbf{2}$ & $\mathbf{3}$ \\
\hline City & & & \\
Miami & 355 & 418 & 473 \\
Minneapolis & 280 & 299 & 331 \\
San Francisco & 246 & 277 & 323 \\
\hline
\end{tabular}

From the results it is obvious for a hotel with more heat demand, installing a chiller worthier than other places.

This is because since CHP can use wasted heat therefore this heat can be converted to cooling type by absorption chiller.

Simulation results confirm this matter since e.g. Miami's hotel which demands lots of heat everyday has more beneficial operation costs in comparison with other cities with less heat demand.

\section{Conclusion}

In this paper an optimal energy dispatch algorithm has been developed for a CCHP-equipped single energy hub system. The algorithm provides the operational signals to the Energy hub system that results in minimum energy cost for users. The model is formulated based on an energy hub modeling. The energy dispatch algorithm has been used in simulations on a model of the energy CCHP-equipped energy hub system at Matlab software. It shows that the algorithm provides the optimal cost throughout the simulation period.

The results from the case study illustrate that absorption cooling may be worth considering if your site requires cooling and waste heat is available, a low-cost source of fuels is available or your site needs more cooling, but has an electrical load limitation that is expensive to overcome, and you have an adequate supply of heat. Each city has to be analyzed separately in order to determine how much the use of CCHP systems is beneficial for this specific location. The model presented in this paper can be used to any type of building. However, each type of buildings have to be analyze and evaluated to determine the optimize conditions, since the electric and thermal load will varied depending on the building type and location.

\section{Acknowledgement}

The authors would like to thank National Institute of Elite of Iran and Institute and Power Research unit of Tavanir for financial and technical support during this research.

\section{References}

[1] Yingjun Ruan et al, "Optimal option of distributed generation technologies for various commercial buildings," Applied Energy 86 (2009) 1641-1653

[2]Heejin Cho at el, "Evaluation of CCHP systems performance based on operational cost, primary energy consumption, and carbon dioxide emission by utilizing an optimal operation scheme" Applied Energy 86 (2009) 25402549
[3]M. Geidl and G. Anderson, "Optimal power flow of multiple energy carrier," IEEE Transaction on Power Systems, vol. 22. no. 1, pp. 145 155, 2007.

[4]US department of energy, energy information administration, glossary. $<$ http://www.eia.doe.gov>.

[5] Strachan N, Farrell A. Emissions from distributed vs. CENTRALIZED generation: the importance of system performance. Energy Policy 2006;34:2677-89.

[6]Strachan N, Dowlatabadi H. Distributed generation and distribution utilities. Energy Policy 2002;30:649-61.

[7] Ackermann T, Andersson , G. Soder L. Distributed generation: a definition. Electric Power Syst Res 2001;57:195-204.

[8]R. Graham and W. Chow, EPRI Project Manager, "Technical and Eco nomic Assessment of Combined Heat and Power Technologies for Commercial Customer Applications", March 2003

[9]L. Wang and C. Singh," Stochastic Combined Heat and Power Dispatch Based on Multi-Objective Particle Swarm Optimization” IEEE Conference 2006.

[10] H. M. Groscurth, T. Bruckner, and R. Kümmel, "Modeling of energy servicessupply systems," Energy, vol. 20, no. 9, pp. 941-958, 1995.

[11]I. Bouwmans and K. Hemmes, "Optimising energy systems-Hydrogen and distributed generation," 2nd Int. Symp. Power System Market Aspects, Stockholm, Sweden, 2002.

[12] R. H. Lasseter and P. Piagi, "Microgrid: A conceptual solution," in Proc. IEEE 35th Annu. Power Electronics Specialists Conf. (PESC), Aachen, Germany, 2004.

[13] R. Frik and P. Favre-Perrod, "Proposal for a multifunctional energy bus and its interlink with generation and consumption," diploma thesis, Power Systems and High Voltage Laboratories, ETH, Zurich, 2004.

[14] M. Geidl, "A greenfield approach for future power systems," in Proc. Cigre Session 41, Paris, France, 2006.

[15] IEA Word Energy Outlook 2010

[16] "2009 Buildings Energy Data Book" by D\&R International, Ltd.

[17] http://www.eia.doe.gov/oil_gas/natural_gas/info_glance/natural_gas.html

[18]http://www.eia.doe.gov/cneaf/electricity/epm/table5_3.html

[19] US department of energy, environmental protection agency, energy star program, target finder. <http://energystar.gov/>.

[20] 2008 ASHRAE Handbook-HVAC Systems and Equipment, ASHRAE 